\title{
ABORDAGEM CTS NA FORMAÇÃo DO TÉCNICO EM QUíMICA: ANÁlISE EM PROJETOS PEDAGÓGICOS DE CURSOS DE DUAS INSTITUIÇÕES PÚBLICAS MATO- GROSSENSES
}

STS APPROACH IN THE TRAINING OF CHEMISTRY TECHNICIANS: ANALYSIS IN PEDAGOGICAL PROJECTS OF COURSES IN TWO PUBLIC INSTITUTIONS IN MATO GROSSO

DOI: 10.23926/RPD.2526-2149.2020.v5.n2.p1111-1123.id742

\section{Leila Cristina Aoyama Barbosa Souza \\ Doutora em Educação \\ Científica e Tecnológica \\ (UFSC) \\ leilasouza@secitec.mt.gov.br}

\section{Edimarcio Francisco \\ da Rocha \\ Doutor em Ciências e \\ Matemática \\ (REAMEC/UFMT) \\ edimarcio.rocha@roo.ifmt.e \\ du.br}

\section{Adriane Barth \\ Doutora em Genética e \\ Biologia Molecular (UESC) \\ adriane.barth@roo.ifmt.edu. br}

\section{Vinicius Batista da \\ Silva \\ Mestre em Educação \\ (UFMT) \\ vinicius.silva@roo.ifmt.edu. br}

\section{Márcio do Nascimento \\ Gomes \\ Mestre em Ciências de \\ Materiais (UFMT) \\ marcio.gomes@roo.ifmt.edu. $\underline{\text { br }}$}

Resumo: A abordagem Ciência, Tecnologia e Sociedade (CTS) no ensino procura explicitar as inter-relações entre tais elementos e se constitui como importante estratégia para a construção do conhecimento científico juntamente com a formação da consciência cidadã dos sujeitos. Neste artigo, analisam-se aspectos dessa abordagem em dois cursos técnicos em Química, subsequentes ao ensino médio de duas instituições públicas mato-grossenses. Para isso, fez-se análise dos Projetos Pedagógicos de Cursos, tendo como referência a pesquisa documental e elementos da análise de conteúdo para o tratamento analítico, buscando por elementos textuais alusivos à abordagem CTS. A interpretação dos textos dos documentos demonstrou não haver a explicitação da abordagem CTS, prevalecendo a formação técnica. Contudo, é possível identificar no discurso que se extrai de fragmentos dos textos, mensagens que remetem à inquietude da formação técnica em contribuir para que se diminuam os impactos do setor produtivo industrial em questões ambientais e sociais.

Palavras-chave: Educação profissional. Alfabetização científica. Formação cidadã.

\begin{abstract}
The Science, Technology and Society (STS) approach to teaching seeks to make explicit the relations between such elements and constitutes an important strategy for the construction of knowledge together with the formation of citizenship' conscience. This article analyzes aspects this approach in two technical courses in Chemistry, subsequent to the high school of two institutions public services in Mato Grosso state. To this end, an analysis was made of the Pedagogical Course Projects, having as reference the documentary research and elements of the content analysis for the analytical treatment, looking for textual elements allusive to the CTS approach. The interpretation of the texts of the documents, demonstrated that there is no explanation of the CTS approach, with technical training prevailing. However, it is possible to identify in the discourse that is extracted from fragments of the texts, messages that refer to the concern of technical training in contributing to reducing the impacts of the industrial productive sector on environmental and social issues.
\end{abstract}

Keywords: Professional education. Scientific literacy. Citizen formation. 


\section{INTRODUÇÃO}

Os documentos oficiais da educação brasileira, independentemente do nível e modalidade aos quais se referem, ressaltam que uma das finalidades da educação é a preparar os sujeitos para o exercício da cidadania (BRASIL, 1996). Por sua vez, especificamente, a educação profissional apresenta outra finalidade integrada a esta anterior: trata-se da qualificação dos educandos para o trabalho. Contemplar ambas as formações (para a cidadania e para o mundo do trabalho) no ambiente escolar é tarefa complexa, principalmente quando vislumbramos a multiplicidade conceitual adquirida pelo termo cidadania.

A ideia de cidadania surge na Grécia e Roma Antigas referindo-se à qualidade daqueles que pertencem à cidade - aqueles que podem participar da vida política. Contemporaneamente, nas sociedades capitalistas do século XX, tal conceito se mantém ao se referir aos direitos políticos adquiridos por todo membro de um Estado-nação democrático (cidadania formal). Entretanto, seu significado evolui para a compreensão de cidadania substantiva ao englobar dimensões diversas desses direitos adquiridos - civis, políticos e sociais (RODRIGUES, 2006).

A função da escola na preparação de seus educandos para a cidadania pode se manifestar de dois modos: o primeiro refere-se à conscientização dos direitos e deveres das pessoas para viver em sociedade - que se aproxima do modelo de educação reprodutivista, isto é, aquela que reproduz os conceitos vigentes da sociedade de maneira a perpetuar a continuidade destes pensamentos/comportamentos; já o segundo, para além da discussão dos direitos e deveres das pessoas como cidadãs, procura conscientizá-las de seu papel em uma participação ativa na sociedade democrática - modelo de educação transformadora. Portanto, aquela que faz parte da sociedade, mas busca, por meio dos condicionantes histórico-sociais, agir para o alcance de uma sociedade justa, igualitária e democrática, principalmente no que diz respeito às dimensões econômica e social (LUCKESI, 1994).

Acreditando no potencial da educação como transformadora da sociedade, em meados das décadas de 1960/70, iniciou-se, na área de Ensino de Ciências, um movimento pela ampla discussão de conteúdos científicos nas escolas (AIKENHEAD, 2005). As discussões deveriam ocorrer a partir de um enfoque social e a fim de contribuir na compreensão dos sujeitos de seu papel como participantes ativos das discussões públicas e tomadas de decisão sobre ciência (AULER, 2011; SANTOS, 2012). Tal abordagem é reconhecida como relações CiênciaTecnologia-Sociedade (CTS). Este campo de conhecimento encontra-se consolidado nas pesquisas educacionais brasileiras, porém sua implementação nas escolas ainda apresenta obstáculos e um contexto educacional desafiador (RICARDO, 2007; MUENCHEN; AULER, 
2007). Tais desafios relacionam-se, principalmente, à estrutura curricular, à organização escolar e à formação docente, constituindo um quadro complexo em que diferentes fatores se articulam. (FERNANDES; STRIEDER, 2017)

O presente estudo tem por objetivo reconhecer a presença da abordagem CTS em Projetos Pedagógicos de Cursos (PPCs) Técnico em Química, modalidade subsequente, de duas instituições públicas do estado de Mato Grosso. A partir disso, desenvolvemos a discussão sobre a importância desse enfoque na formação profissional do técnico em Química.

\section{REFERENCIAL TEÓRICO}

A influência da abordagem CTS no ensino promoveu modificações no currículo, que objetivavam ressignificar a formação tecnocientífica nas escolas (AIKENHEAD, 2005). Ao contrário de um ensino de Ciências voltado à formação de cientistas, modelo esse bastante difundido por influência da Guerra Fria, o ensino permeado pela abordagem CTS, passou a ter como objetivo o aprendizado dos conteúdos de ciências a partir de um contexto real em diálogo com as dimensões sociopolíticas e socioeconômicas. Como desafio para esta implementação havia, sobretudo, a necessidade de superação de um modelo de ensinar ciências fragmentado e focado apenas em conteúdos específicos das disciplinas científicas (PÉREZ, 2014).

Com o passar do tempo, a abordagem CTS no ensino de Ciências assumiu diferentes significações, isto devido às contribuições dos diferentes estudiosos que se dedicaram à pesquisa neste campo. Em relação a esses modos diversos, Pedretti e Nazir (2011) realizaram mapeamento de trabalhos sobre a abordagem CTS no ensino publicados em quatro décadas (1970-2010). Tal mapeamento possibilitou caracterização de seis vertentes de educação CTS, apresentadas resumidamente abaixo:

1. Aplicação e desenho: têm por foco a resolução de problemas por meio do design de novas tecnologias ou da modificação de tecnologias existentes. A educação científica é um utilitário para o desenvolvimento, favorecendo a transmissão de conhecimentos disciplinares.

2. Histórica: busca compreender a inserção histórica e sociocultural das ideias científicas e do trabalho dos cientistas;

3. Raciocínio lógico e argumentação: fazem uso do conhecimento científico para análise de riscos e benefícios de atividades científicas e tecnológicas; 
4. Valores e desenvolvimento moral: buscam a tomada de decisão sobre questões sociocientíficas por intermédio do reconhecimento dos valores relacionados à ética da ciência e ao raciocínio moral;

5. Sociocultural e multiculturalismo: compreendem a ciência e a tecnologia como modelos existentes dentro de um contexto sociocultural mais amplo. Valorizam múltiplos contextos culturais, minorias e dão ênfase aos aspectos afetivos e conhecimentos tradicionais;

6. Justiça socioambiental e formação de ativistas: buscam a formação de cidadãos capazes de agir para transformar a sociedade em direção a maior justiça socioambiental.

Strieder e Kawamura (2017) também mapearam as pesquisas brasileiras sobre educação CTS publicadas na década 2000-2010 e identificaram características que permitiram a elaboração de uma matriz sobre as abordagens CTS adotadas em nosso país. Sinteticamente, tal matriz sinaliza três tipos de propósitos educacionais:

1. Desenvolvimento de percepções: busca a aproximação da sociedade para com Ciência e Tecnologia por meio da aquisição de informações e reconhecimento das relações entre elas. A sociedade passa a estar informada sobre os avanços e problemas mais recentes, ainda que sem avaliar riscos e benefícios;

2. Desenvolvimento de questionamentos: além da contextualização do conhecimento científico, busca-se discutir as implicações do desenvolvimento científico tecnológico na sociedade. Com isso, almeja-se compreender sobre a utilização responsável dos recursos naturais e aparatos tecnológicos. Também, de acordo com esse propósito, o conhecimento científico deixa de ser a finalidade do processo de ensino-aprendizagem e passa a ser entendido como meio para a formação de cidadãos;

3. Desenvolvimento de compromissos sociais: tal modelo de abordagem CTS procura discutir as limitações do conhecimento científico para compreender e resolver os problemas sociais; enfatiza a importância de a sociedade buscar modelos de desenvolvimento que busque satisfazer as necessidades básicas das populações ao invés de apenas valorizar a dimensão econômica; e, buscar uma cultura de participação no âmbito das políticas públicas, na definição de objetivos, meios para alcançá-los e maneiras de controlar sua implementação.

Sendo assim, o ensino fundamentado em abordagens CTS pode apresentar características diversas de acordo com seu objetivo de aprendizagem; podendo assumir caráter mais técnico/reducionista ou mais crítico/formação de cidadania. 


\section{Metodologia}

Esta pesquisa apresenta natureza aplicada - por utilizar conhecimentos existentes e envolver interesses investigativos locais; abordagem de característica qualitativa - uma vez que enfatiza a análise e compreensão de um fenômeno (MINAYO, 2001) e é do tipo exploratório pois proporciona visão geral e informações preliminares sobre o tema investigado (GIL, 2008). Em relação aos procedimentos técnicos para coleta de dados, fez-se uso da pesquisa documental.

A pesquisa documental é uma fonte muito rica de dados qualitativos. Podem ser consideradas fontes documentais: documentos institucionais, cartas, reportagens de jornal, diários, entre outros. A produção de dados, a partir desses documentos, permite que o pesquisador possa conhecer o contexto geral do ambiente de estudo, as experiências e as produções do grupo que ali interage (SAMPIERI; COLLADO; LUCIO, 2013).

Os objetos de pesquisa foram dois PPCs Técnico em Química, modalidade subsequente, de instituições públicas de diferentes esferas, ambas situadas no município de Rondonópolis/MT: o PPC-1 refere-se a um projeto pedagógico do Instituto Federal de Mato Grosso (IFMT) e o PPC-2 a um projeto pedagógico da Escola Técnica Estadual. A obtenção desses documentos se deu por meio de consultas ao site institucional (seleção do PPC-1, 2016) e por aquisição direta junto à coordenação pedagógica da instituição (PPC-2, 2015).

O IFMT é uma autarquia federal, criada através da Lei $n^{\circ} 11.892 / 2008$, vinculada ao Ministério da Educação por meio da Secretaria de Educação Profissional e Tecnológica (SETEC). O campus de Rondonópolis iniciou funcionamento em janeiro de 2011 e, desde o ano seguinte (2012), oferta o Curso Técnico de Nível Médio Subsequente em Química.

Já a Escola Técnica Estadual de Rondonópolis existente desde 2004, integra a rede estadual de educação profissional e tecnológica a partir da oferta de cursos de Formação Inicial e Continuada e cursos de nível técnico. Desde 2013, a instituição atende as demandas locais por meio do Curso Técnico de Nível Médio Subsequente em Química.

A análise apresentada neste trabalho procurou identificar, nos documentos referentes aos cursos técnicos em Química das duas instituições supracitadas, indícios de propostas que associam o conhecimento específico da área técnica com atividades transversais que direcionam para o desenvolvimento do indivíduo quanto a sua responsabilidade social, isto é, evidências de abordagem CTS. Para tanto, o tratamento analítico realizado fundamentou-se na Análise de Conteúdo (BARDIN, 2011). Essa técnica apresenta três fases fundamentais: 1) a pró-análise (que constituiu a leitura flutuante dos PPCs selecionados, a formulação de hipóteses e objetivos 
e a elaboração de indicadores que orientam à interpretação); 2) a exploração do material (que contemplou a fragmentação de trechos e posterior categorização de acordo com suas semelhanças ou por diferenciação); 3) o tratamento dos resultados - a inferência e a interpretação (em que ocorre a condensação e o destaque das informações para análise, culminando nas interpretações inferenciais - momento da intuição, da análise reflexiva e crítica de acordo com os objetivos propostos na Fase 1). As categorias de análise dos PPCs basearamse nos estudos de Pedretti e Nazir (2011) e Strieder e Kawamura (2017).

\section{Resultados}

A leitura dos dois PPCs selecionados indicou, inicialmente, textos alinhados a uma filosofia tecnicista, até mesmo devido à essência que a formação desenvolvida pela educação profissional brasileira apresenta. Contudo, mesmo sendo cursos específicos para a formação profissionalizante, questões vinculadas à preservação ambiental, ética, a contextualização, a interdisciplinaridade e ao convívio social são princípios norteadores da formação técnica de nível médio (BRASIL, 2012) e, assim, são questões inerentes à formação de Técnicos em Química na modalidade Subsequente, que seguem as mesmas diretrizes dos cursos técnicos de nível médio.

Nos projetos pedagógicos, analisamos o texto buscando compreender, em seu discurso, a existência de propósitos educacionais relativos à abordagem CTS.

No quadro 1, apresentamos uma descrição sucinta sobre cada PPC, tendo como base, os respectivos perfis profissionais, justificativas para a implantação dos cursos e objetivos, os quais entendemos que, textualmente, possuem similaridade a elementos que remetem filosoficamente às abordagens CTS.

Quadro 1 - Síntese comparativa dos Projetos Pedagógicos de Cursos (PPCs) selecionados

\begin{tabular}{|c|c|}
\hline PPC-1 & PPC-2 \\
\hline $\begin{array}{l}\text { Curso estruturado em componentes curriculares. } \\
\text { Última atualização em } 2016 .\end{array}$ & $\begin{array}{l}\text { Curso modular estruturado em competências e } \\
\text { habilidades. Última atualização em } 2015 \text {. }\end{array}$ \\
\hline $\begin{array}{l}\text { - Formar profissionais éticos, com senso crítico para } \\
\text { o efetivo exercício da profissão e da cidadania. } \\
\text { - Desenvolvimento de processos sustentáveis em } \\
\text { consonância com o meio ambiente. }\end{array}$ & $\begin{array}{l}\text { - Formar profissionais que saibam analisar as } \\
\text { implicações ambientais relacionadas aos processos } \\
\text { químicos. } \\
\text { - Desenvolver competências para dimensionar a } \\
\text { importância e os aspectos práticos de preservação do } \\
\text { meio ambiente, de maneira ética e responsável, } \\
\text { promovendo melhorias para a qualidade de vida do } \\
\text { cidadão. }\end{array}$ \\
\hline
\end{tabular}

Fonte: Elaborado pelos autores, grifo nosso.

Os apontamentos indicados no Quadro 1 para ambos os PPC, do ponto de vista teórico, podem ser inseridos nos propósitos educacionais indicados por Strieder e Kawamura (2017) em 
relação à abordagem CTS, como sendo do tipo Desenvolvimento de Questionamentos (DQ) e, Desenvolvimento de Compromissos Sociais (DCS). Os textos dos documentos remetem a termos que compreendem o uso responsável dos recursos naturais e à formação para a cidadania, que se enquadram no propósito DQ. Ao proporem o desenvolvimento de aspectos voltados à preservação ambiental, os textos apresentam um discurso que possui enquadramento no propósito DCS, pois os PPCs assumem um caráter de compromisso para a resolução de problemas que abrangem toda a sociedade.

Em outros trechos do PPC-1, é possível identificar diretrizes de formação profissional também voltadas às práticas cidadãs. No Quadro 2, têm-se trechos deste documento indicando como ocorre a articulação de princípios relacionados à abordagem CTS, como, por exemplo, a discussão de valores morais e éticos e a relação sociedade e ambiente.

Tendo como base a matriz de propósitos de Strieder e Kawamura (2017), implicitamente o texto do PPC-1 expõe questões de abordagem CTS. Eis algumas: ao propor formação diferenciada, visando desenvolver a sustentabilidade, direciona a Ciência e a Tecnologia para a resolução de problemas sociais - o que se enquadra na categoria Desenvolvimento de Percepções (DP) ou desenvolver no egresso o senso crítico e promover articulação entre teoria e prática, enquadra-se na categoria $\mathrm{DQ}$, além de afirmar o compromisso da instituição por meio do ensino com a cidadania (categoria DCS). Essas características também possuem relação com a vertente Valores e desenvolvimento moral, conforme Pedretti e Nazir (2011).

Quadro 2 - Fragmentos do PPC-1 que apontam para abordagem CTS

\begin{tabular}{|c|l|}
\hline Item do PPC & \multicolumn{1}{c|}{ Descrição } \\
\hline Justificativa & $\begin{array}{l}\text { "Proporciona [...] formação diferenciada e que atende a atual necessidade de } \\
\text { desenvolvimento de processos sustentáveis, bem como, os cuidados com o meio } \\
\text { ambiente" (p. 16). }\end{array}$ \\
\hline Objetivos & $\begin{array}{l}\text { "Trabalhar de forma articulada conhecimentos teóricos e práticos [...] Desenvolver o } \\
\text { senso crítico [...] Formar profissionais com conceitos éticos, que são indispensáveis } \\
\text { para o exercício da profissão e cidadania" (p. 17). }\end{array}$ \\
\hline Perfil do egresso & $\begin{array}{l}\text { "[...] habilitado para atuar na indústria alimentícia, de bebidas, de tintas, em curtumes, } \\
\text { laboratórios e estações de tratamento de água e esgoto, análises de solos e fertilizantes, } \\
\text { laboratórios de manipulação de matérias primas para farmácias e afins" (p. 28). }\end{array}$ \\
\hline Matriz curricular & "Educação ambiental" (p. 30) tema transversal nas disciplinas. \\
\hline
\end{tabular}

Fonte: PPC-1 (2016), grifo nosso.

Entretanto, ressalta-se ainda por meio dos fragmentos apresentados no Quadro 2, que o texto do PPC-1 demonstra preocupar-se com a formação para o mercado de trabalho. O PPC foi proposto para atender "às necessidades atuais do mercado de trabalho, visando à formação de profissionais cada vez mais capacitados a desenvolverem atividades relacionadas aos processos químicos nos vários setores produtivos" (PPC-1, 2016, p. 17). Ao compararmos este 
último fragmento com o Quadro 2, podemos inferir que a mensagem do texto direciona para uma compreensão de ciência como utilitária, conduzida para a transmissão de conhecimentos. Não foram detectados discursos explícitos que demonstrem a preocupação de formar o cidadão para o mercado de trabalho e sim, formar mão de obra. Do ponto de vista da abordagem CTS, isso se configura como uma vertente de Aplicação e Desenho, indicados por Pedretti e Nazir (2011). Mas convém ressaltar que os professores, por meio de sua experiência profissional e pessoal e de acordo com as correntes teóricas que aplicam, podem estar trabalhando e discutindo tais temáticas de modo mais aprofundado em sala de aula, atingindo o objetivo da formação do cidadão consciente de seu papel em sociedade.

Em relação ao PPC-2 (2015), identificamos que sua matriz curricular é baseada no desenvolvimento de competências e habilidades em desacordo com a Resolução Nº 06/2012 do Conselho Nacional de Educação (BRASIL, 2012). Apesar de este PPC indicar que é previsto no curso o desenvolvimento de valores e atitudes para a melhoria da qualidade de vida, conforme fragmentos do Quadro 3, o documento não aponta como tais ações serão trabalhadas durante a formação profissional a ser desenvolvida.

Quadro 3 - Fragmentos do PPC-2 que indicam a formação para a cidadania

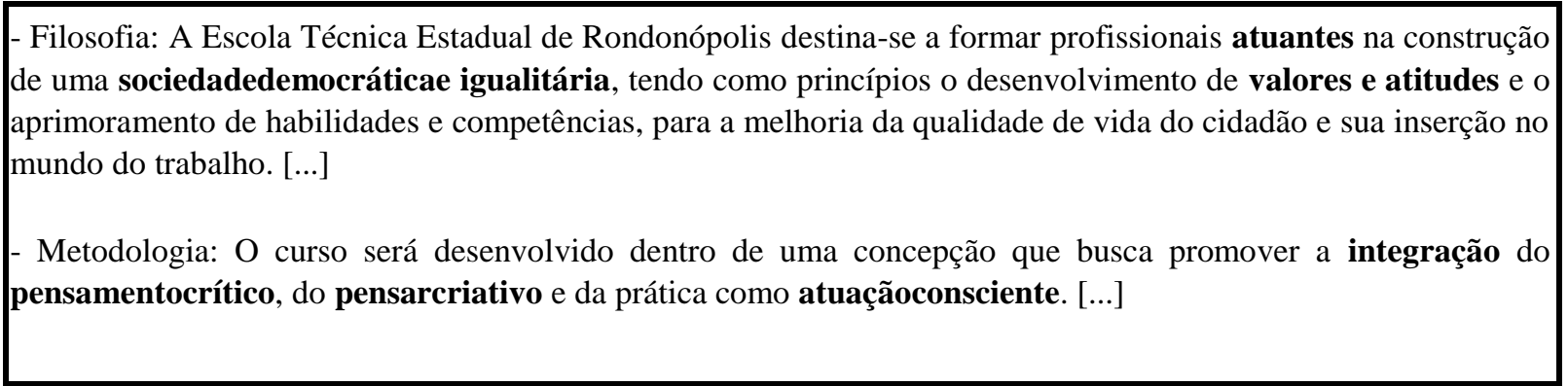

Fonte: PPC-2 (2015), grifo nosso.

Ao observarmos as competências, habilidades e bases tecnológicas constituintes da matriz curricular do PPC-2, conforme Quadro 4, identificam-se, indícios da presença da racionalidade técnica. Como concepção de atuação profissional, tal modelo de racionalidade "consiste na solução instrumental de problemas mediante a aplicação de um conhecimento teórico e técnico, previamente disponível, que procede da pesquisa científica" (CONTRERAS, 2012, p. 101). Isto é, as soluções para os problemas são obtidas a partir do conhecimento preestabelecido, podendo gerar ações mecânicas realizadas sem avaliar a situação vivenciada ou as possíveis consequências destas ações. 
Quadro 4 - Fragmentos da matriz curricular do PPC-2 que indicam racionalidade técnica em disciplinas que envolvem questões ambientais/socioambientais

- Competência 21: Avaliar os aspectos de preservação do meio ambiente e do impacto dos procedimentos laboratoriais.

Habilidade: 21.1. Tratar e descartar resíduos de laboratório.

Bases tecnológicas: - Caracterização qualitativa e quantitativa dos resíduos gerados a partir das análises; [...]; Impactos ambientais decorrentes do descarte dos diversos tipos de resíduos nos efluentes industriais.

- Competência 25: Dimensionar a importância e os aspectos práticos de preservação do meio ambiente, do impacto dos processos industriais e de tratamento de resíduos.

Habilidade: 25.1. Estimar e controlar efeitos ambientais das operações efetuadas.

Bases tecnológicas: - Características físico-químicas do solo, da água e da atmosfera; Resíduos sólidos das classes I e II e suas diferenças.

Competência 26: Interpretar a qualidade do efluente gerado frente aos padrões determinados pelos órgãos de controle.

Habilidade 26.1. Operar sistemas de tratamento de efluentes.

Bases tecnológicas: Características qualitativas e quantitativas dos efluentes gerados nas operações; Impacto dos efluentes de processo nas estações de tratamento ; [...] Tipos de tratamentos físicos, químicos e biológicos de efluentes industriais e suas variáveis de controle; Padrões de lançamento impostos pelos órgãos de controle.

Fonte: PPC-2 (2015), grifo nosso.

Desse modo, foram evidenciados elementos que sinalizam para uma abordagem CTS que privilegia a resolução de problemas da área da indústria química por meio de conhecimentos científicos e tecnologias existentes sem contextualizar e direcionar para a formação da cidadania - aquilo que na classificação proposta por Strieder e Kawamura (2017) se enquadra na categoria DP.

É importante ressaltar que as competências e habilidades que tratam explicitamente sobre questões ambientais na matriz curricular analisada - demonstradas no Quadro 3 - podem ser reestruturadas de maneira a contemplar abordagens CTS mais amplas, isto é, aquelas que contemplam dimensões para além do conhecimento técnico científico. A exemplo, as competências 25 e 26 que tratam sobre controle de resíduos sólidos e de efluentes, respectivamente, poderiam abordar reflexões sobre o que é considerado seguro ou de menor risco nas atividades químicas bem como os valores éticos das atividades científicas e tecnológicas e sua relação com as dimensões política e econômica do modo de produção vigente. Tais discussões podem ser promovidas por meio das questões sociocientíficas e o campo disciplinar da Química é rico em conteúdos com potencialidades para este fim. Conforme explica Santos (2007), temas que tratam de problemas ambientais - como a poluição hídrica, o uso de agrotóxicos, o descarte de resíduos sólidos e a poluição atmosférica - podem 
ser contextualizados à realidade local e serem abordados em uma associação entre conteúdos químicos e aspectos sociais, econômicos, éticos e ambientais.

\section{CONSIDERAÇõES FINAIS}

Os documentos oficiais brasileiros que regulamentam o ensino técnico de nível médio indicam a formação de profissionais atentos à solução de problemáticas ambientais, bem como pela manutenção de um meio ambiente equilibrado e saudável, pelo uso da responsabilidade socioambiental (BRASIL, 2012). Isso significa que os sujeitos formados em cursos técnicos precisam ser estimulados a pensar em seu trabalho como elemento constituinte de uma cadeia produtiva que interfere, direta ou indiretamente, sobre o meio ambiente e sociedade. Tais características condizem com o ensino pela abordagem CTS ao relacionar o conhecimento científico e tecnológico à dimensão socioambiental. Todavia é importante ressaltar que a abordagem CTS defendida neste trabalho é aquela que busca o compromisso social dos estudantes com o meio ambiente, de modo a desenvolver sua consciência para a justiça ambiental e atitudes que promovam o ativismo e protagonismo da sociedade junto às atividades científicas e tecnológicas.

Nossa análise de dois PPCs de Técnico em Química, modalidade subsequente, de duas instituições mato-grossenses identificou que a essência dos documentos se constitui de um modelo em que prevalece o ensino tradicional e conteudista. O currículo dos cursos, embora diferentes, convergem para a tecnocracia e, mesmo que por similaridade apresentem questões pontuais em que se percebe a abordagem CTS, precisam ser repensadas e ajustadas às necessidades de formar de fato, cidadãos que reflitam sobre as ações que estão desenvolvendo. No discurso explícito, os PPCs analisados, em diversos momentos, incentivam o trabalho do Técnico em Química na perspectiva de resoluções de problemas dissociados das dimensões socioambiental e sociocientífica. A exemplo disso, a exploração dos recursos naturais pelos modos de produção de maneira irresponsável e o desenvolvimento tecnológico que privilegia muitas vezes os detentores do capital, resultam em impactos que alcançam toda a sociedade e que perpassa situações que são intrínsecas à formação educacional dos indivíduos.

A abordagem CTS constitui um meio para que aquilo que é ensinado, tenha valor na cidadania e na contextualização histórica dos fenômenos, rompendo com modelos tradicionais que contribuem para a formação de indivíduos obtusos ao meio em que vivem e que não conseguem, por exemplo, estabelecer relações entre situações cotidianas de sua realidade e os conceitos estudados. Como exemplo, observa-se que muitos estudantes não conseguem 
estabelecer relação entre a falta de recursos hídricos ou a diminuição de sua oferta com processos de desmate para a implementação de lavouras.

Entendemos que a divergência entre o discurso de elementos dos PPCs - como objetivos e perfis profissional dos egressos - e a matriz curricular possa estar sendo amenizada em sala de aula a partir do trabalho de professores que compreendem a necessidade da abordagem CTS na perspectiva crítica; uma vez que o currículo real supera o currículo prescrito na matriz curricular - que por vezes manifesta racionalidade técnica. Outra hipótese a ser considerada para os resultados encontrados diz respeito ao modo como os PPCs são construídos. Em geral, os professores que ministram as disciplinas são responsáveis pela atualização da matriz curricular e podem não estar se atentando aos princípios educativos da instituição. Tal fato sinaliza a necessidade da formação continuada e permanente dos professores.

Com esta reflexão, esperamos o desencadeamento de ações nas instituições públicas de educação profissional do estado de Mato Grosso que permitam ampliar as discussões sobre o tema e possibilitar reformulações curriculares. Quanto a isso, ressaltamos que, dando continuidade a esta pesquisa, as próximas etapas contemplam o desenvolvimento de atividades formativas com os professores das instituições analisadas com vista às discussões sobre potencialidades das dimensões sociocientífica e socioambiental no ensino técnico, pois há o entendimento do papel docente como partícipes da elaboração dos itinerários formativos dos cursos técnicos e de sua atuação no ensino em sala de aula.

\section{REFERÊNCIAS}

AIKENHEAD, Glen. Educación ciencia-tecnología-sociedad (CTS): una buena idea como quiera que se le llame. Educación Química, v. 16, n. 2, p. 304-315, 2005. Disponível em: https://andoni.garritz.com/documentos/aikenhead_a_rose_by_any_other_name.pdf. Acesso em: 21 maio 2020.

AULER, Décio. Novos caminhos para a educação CTS: ampliando a participação. In: SANTOS, Wildson Luiz Pereira dos; AULER, Décio. (orgs). CTS e educação científica: desafios, tendências e resultados de pesquisa. Brasília: Editora UnB, 2011. p. 73-97.

BARDIN, Laurence. Análise de conteúdo. São Paulo: Edições 70, 2011.

BRASIL. Resolução n. ${ }^{\circ}$ 6, de 20 de setembro de 2012. Diretrizes Curriculares Nacionais para a Educação Profissional Técnica de Nível Médio. Diário Oficial da União, Brasília, 21 set. 2012, Seção 1, p. 22. Disponível em:

http://portal.mec.gov.br/index.php?option=com_docman\&view=download\&alias=11663rceb006-12-pdf\&category_slug=setembro-2012-pdf\&Itemid=30192. Acesso em: 21 maio 2020. 
BRASIL. Lei n. ${ }^{\circ}$ 9.394, de 20 de dezembro de 1996. Estabelece as Diretrizes e Bases da Educação Nacional. Diário Oficial da União, Brasília, 23 dez. 1996. Disponível em: http://portal.mec.gov.br/seesp/arquivos/pdf/lei9394_ldbn1.pdf. Acesso em: 02 fev. 2020.

CONTRERAS, José. Autonomia de professores. 2. ed. São Paulo: Cortez, 2012.

FERNANDES, Roseane Freitas; STRIEDER, Roseline Beatriz. Dificuldades enfrentadas por professores na implementação de propostas CTS. In: ENCONTRO NACIONAL DE PESQUISA EM EDUCAÇÃO EM CIÊNCIAS, 11, 2017, Florianópolis.

Anais...Florianópolis: UFSC, 2017. p. 1-9. Disponível em: http://www.abrapecnet.org.br/enpec/xi-enpec/anais/resumos/R1953-1.pdf. Acesso em: 19ago.2020.

GIL, Antônio Carlos. Métodos e técnicas de pesquisa social. 6. ed. São Paulo: Atlas, 2008. LUCKESI, Cipriano Carlos. Filosofia da Educação. São Paulo: Cortez, 1994.

MINAYO, Maria Cecília de Souza. (org.). Pesquisa Social: teoria, método e criatividade. 18. ed. Petrópolis: Vozes, 2001.

MUENCHEN, Cristiane; AULER, Décio. Configurações curriculares mediante o enfoque CTS: desafios a serem enfrentados na educação de Jovens e Adultos. Ciência \& Educação, v. 13, n. 3, p. 421-434, 2007. Disponível em: https://www.scielo.br/pdf/ciedu/v13n3/a10v13n3.pdf. Acesso em: 19 ago. 2020.

PEDRETTI, Erminia; NAZIR, Joanne. Currents in STSE Education: mapping a complex field, 40 years on. Science Education, v. 95, n. 4, p. 601-626, 2011.

PÉREZ, Leonardo Fabio Martínez. Cuestiones sociocientíficas en la formación de profesores de ciencias: aportes y desafíos. Tecné, Episteme y Didacxis, n. 36, p. 77-94, 2014. Disponível em: https://revistas.pedagogica.edu.co/index.php/TED/article/view/2913/2634. Acesso em: 25 out. 2019.

PPC-1. Projeto Pedagógico do Curso Técnico em Química Subsequente ao Nível Médio. Rondonópolis: IFMT, 2016.

PPC-2. Projeto Pedagógico do Curso Técnico em Química. Rondonópolis: SECITECI, 2015.

RICARDO, Elio Carlos. Educação CTSA: obstáculos e possibilidades para sua implementação no contexto escolar. Ciência \& Ensino, vol. 1, número especial, nov. 2007. Disponível em: https://edisciplinas.usp.br/pluginfile.php/4146732/mod_resource/content/2/EDUCA\%C3\%87 \%C3\%830\%20CTSA-OBST\%C3\%81CULOS.pdf. Acesso em: 19 ago. 2020.

RODRIGUES, José. Qual cidadania, qual democracia, qual educação? Trabalho, Educação e Saúde, v. 4, n. 2, p. 417-430, 2006. Disponível em:

https://www.scielo.br/pdf/tes/v4n2/12.pdf. Acesso em: 20 jan. 2020.

SAMPIERI, Roberto Hernandez; COLLADO, Carlos Fernández; LUCIO, María del Pillar Baptista. Metolodogia de Pesquisa. 5. ed. Porto Alegre: Penso, 2013. 
SANTOS, Wildson Luiz Pereira dos. Contextualização no ensino de ciências por meio de temas CTS em uma perspectiva crítica. Ciência \& Ensino, Campinas, v. 1, n. esp., p. 1-12, 2007. Disponível em: http://files.gpecea-usp.webnode.com.br/200000358-

0e00c0e7d9/AULA\%206-\%20TEXTO\%2014-

\%20CONTEXTUALIZACAO\%20NO\%20ENSINO\%20DE\%20CIENCIAS\%20POR\%20M EI.pdf. Acesso em: 02 mar. 2020.

SANTOS, Wildson Luiz Pereira dos. Educação CTS e cidadania: confluências e diferenças. Amazônia: Revista de educação em ciências e matemáticas, v. 9, n. 17, p. 49-62, 2012. Disponível em: https://periodicos.ufpa.br/index.php/revistaamazonia/article/view/1647/2077. Acesso em 19 fev. 2020.

STRIEDER, Roseline Beatriz; KAWAMURA, Maria Regina Dubeux. Educação CTS: parâmetros e propósitos brasileiros. Alexandria: Revista de Educação em Ciência e Tecnologia, v. 10, n. 1, p. 27-56, 2017. Disponível em:

https://periodicos.ufsc.br/index.php/alexandria/article/view/1982-5153.2017v10n1p27/34216. Acesso em: 02 mar. 2019.

Recebido em: 4 de junho de 2020.

Aprovado em: 18 de agosto de 2020. 